\title{
Frameworks for Digital Competence Assessment: Proposals, Instruments, and Evaluation
}

\author{
Antonio Cartelli \\ University of Cassino, Cassino, Italy
}

cartan@unicas.it

\begin{abstract}
After a short introduction on the need for a new literacy, coming from the work of many organizations and institutions during last twenty years, the approach adopted by an Italian research group for the planning and development of a framework for digital competence assessment is discussed. This model, the first built until now, has been used to create a questionnaire experimented with High School students and has been discussed with colleagues in conferences and meetings. The criticisms and amendments which have been proposed led to a new framework, which has the main feature of being centred on the subject while focussing the analysis of the digital competence, more than adopting a discipline (IT/ICT) centred approach for its assessment, like in the first framework.

In the next section of the paper the different dimensions of the framework are discussed. First the cognitive dimension is analyzed and the questionnaire developed by the organizing committee of the "Beaver" international competition to assess IT/ICT knowledge and skills in students, is proposed for the assessment of the cognitive dimension of digital competence. The discussion of the answers that two groups of students of different ages (i.e., Benjamin and Junior) gave to this questionnaire follow, and the differences in the two age groups are reported. Furthermore the answers to the questions for the assessment of the affective dimension of the framework are discussed.

In the conclusion it is shown how and why the main features of the new framework can be considered to fit the required assessment of digital competence and some hints for the direction of future studies and research are given.
\end{abstract}

Keywords: assessment, digital literacy, digital competence, educational taxonomy.

\section{Introduction}

Material published as part of this publication, either on-line or in print, is copyrighted by the Informing Science Institute.

Permission to make digital or paper copy of part or all of these works for personal or classroom use is granted without fee provided that the copies are not made or distributed for profit or commercial advantage AND that copies 1) bear this notice in full and 2) give the full citation on the first page. It is permissible to abstract these works so long as credit is given. To copy in all other cases or to republish or to post on a server or to redistribute to lists requires specific permission and payment of a fee. Contact 0HPublisher@InformingScience.org to request redistribution permission.
Since twenty years ago many organizations and institutions made different attempts to specify the features of the literacy needed in today society; it is in fact continuously changing, due to the increasing and relevant presence of computers and digital equipments in all aspects of our life.

First the statement "digital divide" has been adopted, it highlights the difference between developed and underde- 
veloped countries in the access to digital equipment (i.e., between people who have easy access to digital resources and information and those who have no access to them).

More recently the debate on the need for suitable computing/communication skills in young generations has been intertwined with the features of the digital divide in developed countries (Bindé et al., 2005; Guidolin, 2005), and especially with the following elements:

a) the gap due to pre-existing differences between people who can use (are able in the use of) technologies and people who cannot,

b) the gap in the content management between people who master it (i.e., subjects who are able in the use of ICT to manage information, knowledge, know how etc.), and those who cannot.

Until the digital divide was identified with the lack of equipment and how to use it, the definition of computing syllabi and the creation of systems for the certification of the basic knowledge and skills people must have to be considered computer literate looked suitable. The CEPIS (Council of European Professional Informatics Societies), at least in Europe, fully adopted these ideas, and developed curricula for computer users and professionals. Two different IT skill certifications were developed by CEPIS: the European Computer Driving Licence (ECDL), at a basic level, and the European Certification of Informatics Professionals (EUCIP), at a higher level. Today many criticisms are focussed on the above certifications, because they usually assess people's ability in the use of well given instruments and programs, and don't analyze the impact of the whole set of computing instruments and methods on people's communication skills and competences.

On another hand, the introduction of a suitable literacy at school or, more generally, for every citizen in a perspective of lifelong learning, has been considered the best choice for the creation of a sound digital culture. On this side it can be easily understood how and why public institutions like Associations of Libraries, OCSE and UNESCO, intensively worked at the definition of different "literacies", like information literacy, computing literacy, IT and ICT literacy, digital literacy and media education.

Very recently a comprehensive definition for digital literacy has been proposed by Martin (2005), when working on the European research project DigEuLit (http://www.jelit.org/). Martin and his colleagues remarked that digital literacy includes several key elements:

1) being able to carry out successful digital actions embedded within life situations, which may include work, learning, leisure, and other aspects of everyday life,

2) to vary according to a subject's particular life situation, and to be an ongoing lifelong process, developing as the individual's life situation evolves,

3) to be broader than ICT literacy and to include elements drawn from several related "literacies", such as information literacy, media literacy and visual literacy,

4) to involve acquiring and using knowledge, techniques, attitudes and personal qualities, and to include the ability to plan, execute and evaluate digital actions in the solution of life tasks, and the ability to reflect on one's own digital literacy development.

On these bases the DigEuLit team drew the following definition: "Digital Literacy is the awareness, attitude and ability of individuals to appropriately use digital tools and facilities to identify, access, manage, integrate, evaluate, analyse and synthesize digital resources, construct new knowledge, create media expressions, and communicate with others, in the context of specific life situations, in order to enable constructive social action; and to reflect upon this process" (Martin, 2005).

A different approach to the analysis of the impact that new technologies have on mankind is obtained when the attention is centred on how people use digital resources and processes, more than on what they must know and be able to do with technologies; in such a case the concept of com- 
petence and the active involvement of the subjects with their representations of reality, their knowledge and skills become much more important (Le Boterf, 1990).

One of the most recent and important interventions on this regard comes from the European Commission. In 2005, in fact, it issued the Recommendation on key competences for lifelong learning and stated the features for the digital competence, the fourth among them (Commission of the European Parliament, 2005). For the European Commission the digital competence is based on the confident and critical use of Information Society Technology (IST) for work, leisure and communication and is underpinned by basic skills in ICT: that is the use of computers to retrieve, assess, store, produce, present and exchange information, and to communicate and participate in collaborative networks via the Internet.

The presence of digital competence is intertwined with:

a) the understanding and knowledge of the nature, role and opportunities of IST in everyday contexts: in personal and social life as well as at work. It includes main computer applications, a sound use of the Internet and the communication via electronic media for leisure, information sharing and collaborative networking, learning and research,

b) the understanding of the support that creativity and innovation can receive from IST, the development of sound understanding skills helping state if information is valid, reliable and affordable enough and the knowledge of the ethical principles for the interactive use of IST.

On the basis of the above definition of digital competence Calvani and the equip made by researchers and scholars in the Italian Universities of Florence, Turin, Salerno and Cassino, decided to better analyze these competences and to create the instruments for their assessment.

People in the research group agreed on the following features for digital competences:

- they are multidimensional, because they imply the integration of cognitive, relational and social abilities and skills,

- they are complex and evolve with time,

- they are interconnected, because they are not independent from other key competences like reading, numeracy, problem solving, inferential skills etc.

- they are sensitive to the socio-cultural context, because their meaning can change over time, according to the context and to different educational settings.

The above features for digital competences looked general and wide enough to be the basis for the sound development of analysis instruments, survey strategies and further investigation.

First, three levels of analysis were proposed: search for information, problem solving, and collaborative knowledge building. Soon after a framework for digital competence assessment was developed (Calvani et al., 2008); it is based on the co-existence of three different dimensions intersecting one another, as reported in Figure 1:

I. technological: that is, being able to explore and face problems and new technological contexts in a flexible way;

II. cognitive: which means reading, selecting, interpreting and evaluating data and information, while considering their pertinence and reliability;

III. ethical: which is expressed by the interaction with other individuals in a constructive way and with sense of responsibility (by using the available technologies); 
the integration of the above three dimensions is also possible and is based on the understanding of the potential offered by technologies, which lets individuals share information and collaboratively build new knowledge.

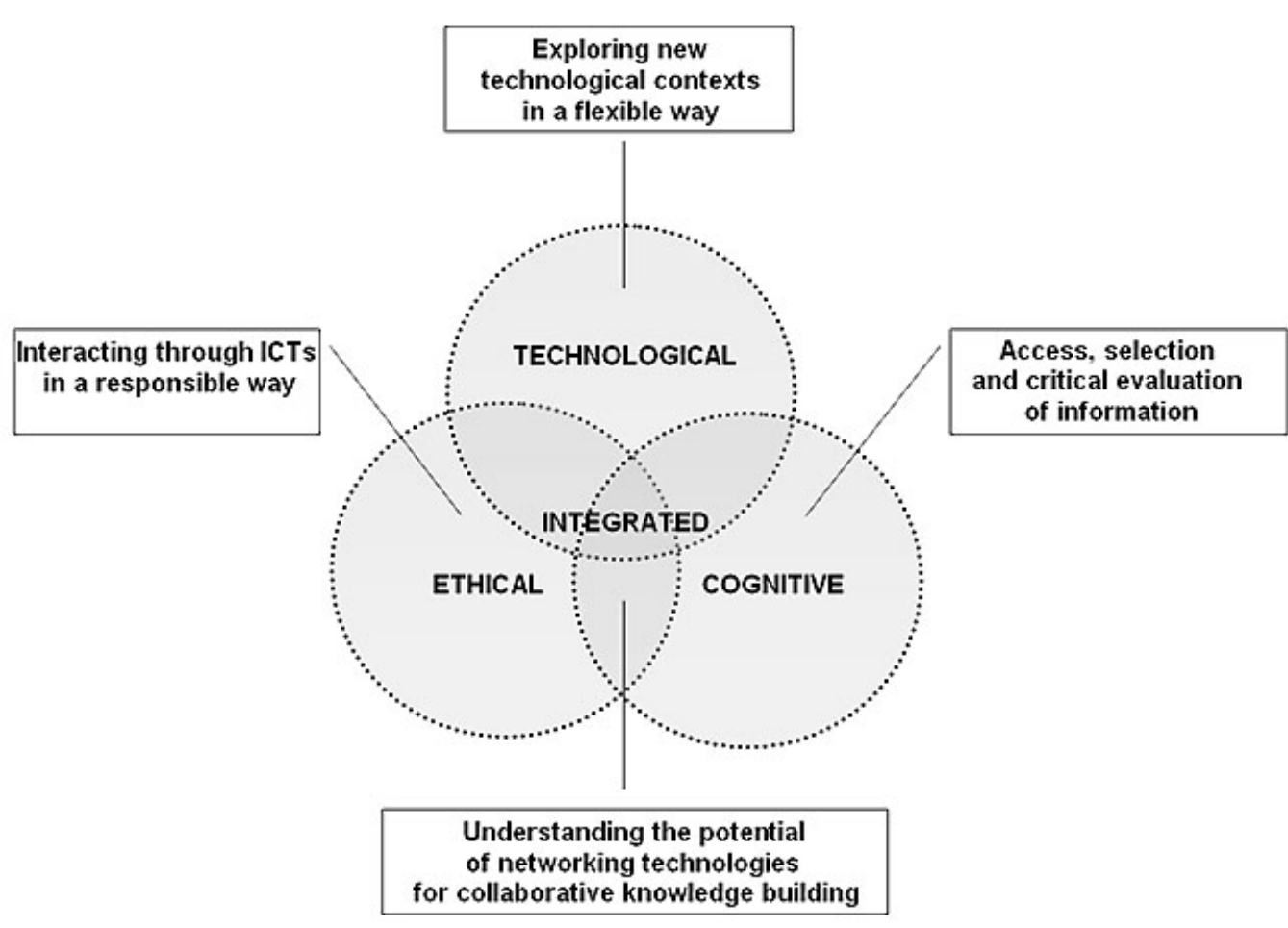

Figure 1: First hypothesis for a digital competence assessment framework

\section{The Need of a New Framework for Digital Competence Assessment and Its Instruments}

The analysis of the answers that a sample of students gave to the questionnaire for digital competence assessment (more than 200 young people in Italian High School aged from 16 to 19 years), developed under the hypothesis of the framework in figure 1, evidenced many limits in that model. Furthermore, the discussions with teachers and researchers, in national and international workshops and conferences, where the framework and the answers of the students were reported and analyzed, confirmed those limits and led to the revision and rebuild of the model.

The most relevant criticisms can be synthesized in the items below (Cartelli, 2009):

1. the ethical dimension looked more normative than descriptive, and it was very difficult if not impossible to measure and assess the possible competences it dealt with,

2. both technological and cognitive dimensions produced questions in the cognitive domain,

3 . the absence of the affective and socio-relational dimensions was remarked; on the contrary, some questions looking to pertain to these issues were present in the different dimensions of the framework. 


\section{Towards a New Model for Digital Competence Assessment}

The main idea guiding the creation of the new framework is the central position that subjects must have in the analysis of the phenomena concerning the interaction between digital technologies and human beings; this perspective completely reverted the discipline centric perspective (IT/ICT centred), adopted in the first framework for the study of phenomena.

The first model for digital competence assessment was in fact highly influenced by the results from different computer science fields:

a) $\mathrm{HCI}$ (Human Computer Interaction), which played a special role,

b) the presence of a netiquette in CMC (Computer Mediated Communication), and the socio-psychological studies on it,

c) the studies on the social effects of computing.

By assuming an anthropocentric perspective for the development of the framework, the results from psycho-pedagogical literature could not be neglected or left on the background, and the well known educational taxonomies for the assessment of learning and for knowledge construction and evolution (Bloom et al., 1956), had to be adopted.

With these assumptions it has been hypothesized that the new model for the framework of digital competence assessment is based on the following dimensions: cognitive, affective and sociorelational.

The new cognitive dimension in the framework unifies the cognitive and technological dimensions reported in the former model. The main elements governing the assessment in the new cognitive dimension are the Bloom categories: knowledge, comprehension, application, analysis, synthesis, evaluation (Bloom et al., 1956). A finer breakdown of the elements to be intertwined with digital competences in the cognitive dimension led to the specification of the following elements:

a) the verbal-linguistic and logical-mathematical competences, deduced by the corresponding Gardner intelligences (Gardner, 1993), to be seen as special sections in the dimension; they are very important together with technological competences when people use digital equipment for the construction of new knowledge, the creation of media expressions, and communication with others, in the context of specific life situations, as suggested by Martin (2005),

b) the skills derived from the construction and evolution of the concepts of space, time and causality (Piaget 1970); which act as categories on the above sections. This last issue is the consequence of the space dilatation and time contraction usually experienced by people when interacting with the web, and can also be detected in the loss of causality, which can be experienced in the answer to people queries by search engines, when word matching strategies are adopted.

In the affective dimension the Krathwohl taxonomy (Krathwohl et al., 1973) has been adopted. It is based on the following categories for the assessment of facts and experiences: receiving phenomena, responding to phenomena, evaluating, organizing and internalizing phenomena.

At last the socio-relational dimension has been introduced to assess human and social interactions and relations; the problem with this dimension is the lack of a well accepted and shared definition of its features.

The new framework based on the reported dimensions: cognitive, affective and socio-relational, is reported in Figure 2 (Cartelli, 2009). As explained before, cognitive competences are split in three sections: technological, verbal-linguistic and logical-mathematical, all under the umbrella of space, time and causality categories. In the figure are also reported the affective and the socio- 
relational dimensions; this last one, still to be deeply studied, analyzed and described, is thought under the influence of interpersonal and intrapersonal interactions of the subjects.

As in the former model, the area in the intersection of the three dimensions depends on the understanding and use of the potential of networking technologies for collaborative knowledge building. More generally this common area can be considered responsible for the ability of being an active part in the creation and development of communities of learning and practices.

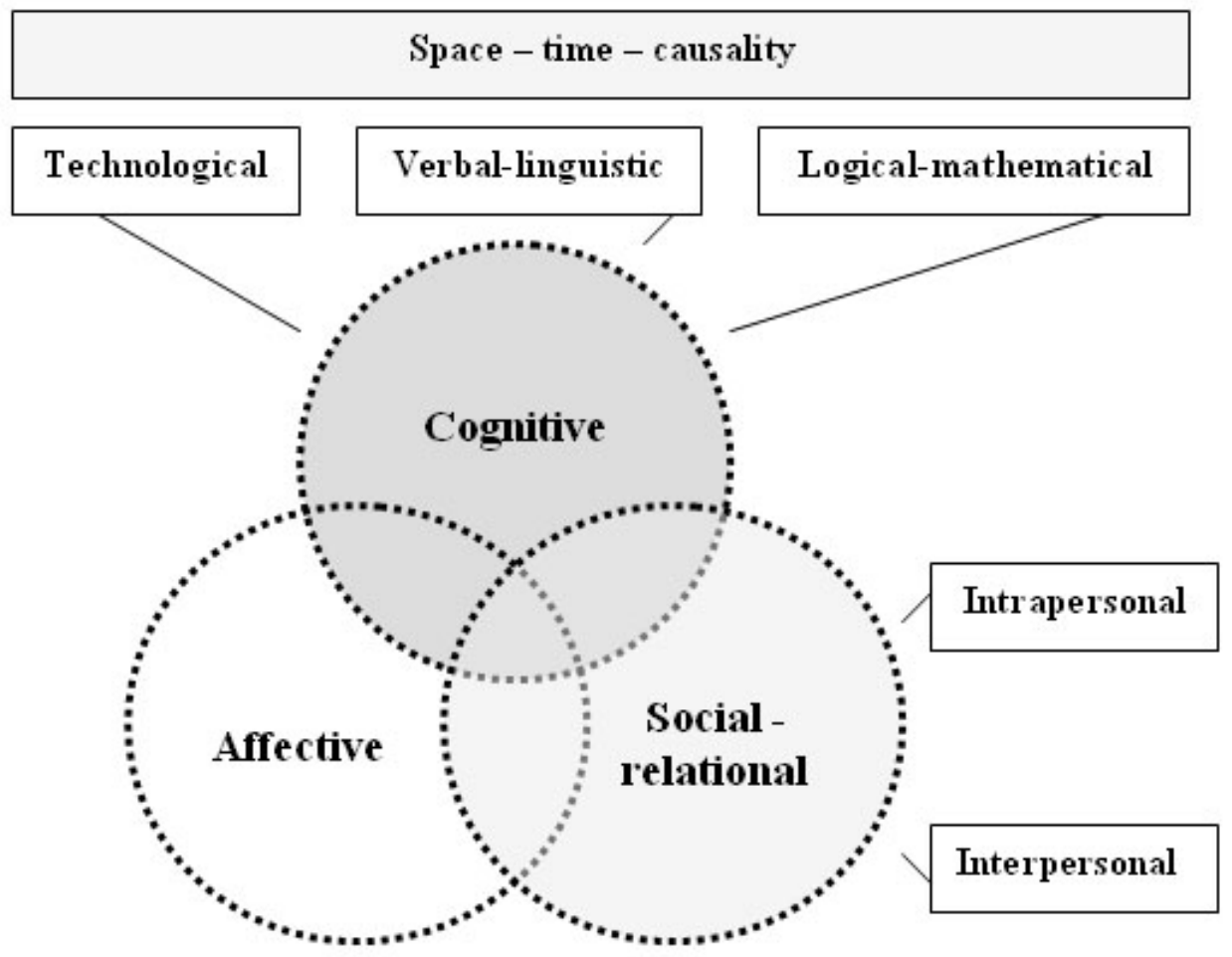

Figure 2: The new digital competence assessment framework

At the end of the short description of this new framework for digital competence assessment it has to be noted that some theoretical bases for it are derived from the theories of Gardner (1993) and Janney \& Snell (2006). From Gardner have been borrowed the intrapersonal (introspective and self-reflective skills and capacities) and interpersonal intelligences (capacity of interacting with others and being sensible to their needs, ability in working in a group); they introduced a separation between the self-analysis and the analysis of the interaction with others. Janney and Snell, on another hand, led to the application to the digital divide of the methods and strategies they adopted for the analysis of the interaction between students with disabilities and other students.

\section{The Instruments for Digital Competence Assessment}

Once the new framework ready what instruments had to be adopted for digital competence assessment? While working on the first model different hypotheses emerged (i.e., a questionnaire for quantitative analysis, and situated and projective tests for qualitative analysis); now the questionnaire looked the best instrument for the following reasons:

a) its immediateness,

b) its adaptability and portability to different situations and groups of students, 
c) its ease of use both on paper and electronically (due to the opportunity of being easily reviewed and modified),

d) the fast acquisition of feed-back information from the analysis of students' answers, which can lead to the development of suitable instruments, helping students and teachers to better understand phenomena and to plan teaching-learning situations for special digital knowledge and skills,

e) the help coming from the work of well organized groups of colleagues, who developed and still are developing the questionnaire for the yearly "Beaver" international competition, devoted to the analysis of IT/ICT competences (Cartelli et al., in press); this instrument, as will be shown below, has proven to be very useful for the analysis of the cognitive dimension of the framework.

Until now it is impossible to give the complete structure of the questionnaire due to the lack of the features of the socio-relational dimension in the framework. It doesn't mean that a tentative of questionnaire, also partial, has not been carried out; the prototype that the author developed is made of only two sections: the cognitive and the affective.

The questions in the cognitive dimension of the framework come from the questions in the "Beaver" contest, because most part of them conform to the technological, logical-mathematical and verbal-linguistic sections and are submitted to the space, time and causality categories. Moreover the simple rules of the "Beaver" contest led the author develop a questionnaire or part of it, to be used both for the assessment of the students' digital competences and the participation of the same students to the international competition.

To better understand how and why the questionnaire for the "Beaver" contest is compliant with the cognitive section of the questionnaire for digital competence assessment some features of the competition are reported below:

a) the contest takes place in every country during the same time period (or very close one each other), and an annual meeting is devoted to the choice and approval of the questions to be used that year; the selected questions are grouped into three score classes (easy, medium and hard), and are included in a repository which can be freely used from every national team. A given set of questions is democratically selected to be mandatory for everyone (i.e., they must be included in all national questionnaires),

b) every question in the "beaver" questionnaire (made of $18-27$ questions) is translated in the national language and is structured as an interactive task or as multiple-choice question,

c) the students taking part in the contest are grouped into at least three age groups called: Benjamin (primary school students, i.e., pupils aged from 10 to 12), Junior (students with some IT/ICT basic knowledge, from 13 to 15 years old) and Senior (upper secondary school students, from 16 to 19 years old).

As regards the affective dimension a first attempt has been made for the questions to be introduced in the questionnaire. By adopting Krathwohl taxonomy five levels, moving through the lowest order processes to the highest, have been considered:

- receiving - the lowest level; the student passively pays attention; without this level no learning can occur,

- responding - the student actively participates in the learning process, not only attends to a stimulus, also reacts in some way,

- valuing - the student attaches a value to an object, phenomenon, or piece of information,

- organizing - the student can put together different values, information, and ideas and accommodate them within his/her own schema; comparing, relating and elaborating on what has been learned, 
- characterizing - the student holds a particular value or belief that now exerts influence on his/her behavior so that it becomes a characteristic.

To hit the target of assessing this dimension three levels of analysis have been hypothesized:

a) the level of attention/impression towards some selected questions in the cognitive dimension (what question do you think more impressive among the selected ones and why?),

b) the level of all the questions in the cognitive dimension (what problem do you find more impressive/interesting? Who can help you better understand the situations described in the reported questions?),

c) the level of attention towards possible digital equipment different from those reported in the questionnaire (what questions and what situations/equipment did you include in the questionnaire?).

At last, nothing has been proposed for the assessment of the socio-relational dimension.

\section{Students' Answers and the Framework for Digital Competence Assessment}

In 2009 Italy has been included for the first time in the organizing committee of the "Beaver" competition and the author could work to the preparation of the questions for the contest together with the colleagues of the other countries. The amount of work to be made and the little number of persons involved in the management of the Italian chapter of the competition suggested to limit to the first two age groups of students, Benjamin and Juniors.

Once the repository of the "Beaver" competition was ready, a careful selection of the questions was made on the basis of the framework reported in figure 2 (i.e., only the cognitive dimension was involved in the choice of the "Beaver" questions) and the two questionnaires were made up (two sets of 18 questions each, grouped in three different levels of difficulty have been translated in Italian and collected in the corresponding questionnaires). Two groups of five questions, one for each questionnaire, were considered representative of the most relevant aspects of the cognitive dimension (verbal-linguistic, logical-mathematical and technological sections and space, time and causality categories). The second section of the questionnaires, devoted to the assessment of the affective dimension and almost identical for the two groups of students, was included in the Italian questionnaire, but was not used from the other "Beaver" national teams.

It is behind the aims of this paper the discussion of the strategies adopted for the carrying out of the competition, that is, how to invite schools and persuade teachers and students to participate in the contest and how to manage the collection of the answers of the students; nevertheless, it can be useful to remark that the e-learning platform Moodle has been used to implement the questionnaires and manage the teachers' and the students' access to the contest. The system supporting the platform succeeded in facing the contemporary access of the students' classes and no problem was detected during the competition, at least from the web server side.

The global datum obtained from the data stored in the Moodle database shows that 176 Benjamin students and 92 Junior students accessed the system and answered the questionnaires.

In what follows the answers from the students who took part in the competition are analyzed and the suggestions for the future are discussed.

\section{Students' Answers in the Knowledge Dimension}

As regards the cognitive dimension of the framework, the table below reports some data on the answers of the Benjamin students (Table 1): 


\begin{tabular}{|l|c|}
\hline \multicolumn{2}{|c|}{ Table 1. Distribution of the Benjamin students' answers } \\
\hline Description & Percentage \\
\hline $\begin{array}{l}\text { Question 1 obtained the worst result (lowest number } \\
\text { of right answers) }\end{array}$ & $22 \%$ \\
\hline $\begin{array}{l}\text { Question 2 obtained the best result (highest number of } \\
\text { right answers) }\end{array}$ & $89 \%$ \\
\hline $\begin{array}{l}\text { Medium percentage of positive answers to all other } \\
\text { questions }\end{array}$ & $55 \%$ \\
\hline $\begin{array}{l}\text { Percentage of right answers to all the questions in the } \\
\text { set of those selected (most representative) }\end{array}$ & $10 \%$ \\
\hline $\begin{array}{l}\text { Percentage of right answers to all the questions in the } \\
\text { cognitive section of the questionnaire }\end{array}$ & $5 \%$ \\
\hline
\end{tabular}

Table 2 reports the analogous situation for the Junior students:

\begin{tabular}{|l|c|}
\hline \multicolumn{2}{|c|}{ Table 2. Distribution of the Junior students' answers } \\
\hline Description & Percentage \\
\hline $\begin{array}{l}\text { Question 5 obtained the worst result (lowest number } \\
\text { of right answers) }\end{array}$ & $48 \%$ \\
\hline $\begin{array}{l}\text { Question 12 obtained the best result (highest number } \\
\text { of right answers) }\end{array}$ & $89 \%$ \\
\hline $\begin{array}{l}\text { Medium percentage of positive answers to all other } \\
\text { questions }\end{array}$ & $70 \%$ \\
\hline $\begin{array}{l}\text { Percentage of right answers to all the questions in the } \\
\text { set of those selected (most representative) }\end{array}$ & $15 \%$ \\
\hline $\begin{array}{l}\text { Percentage of right answers to all the questions in the } \\
\text { cognitive section of the questionnaire }\end{array}$ & $3 \%$ \\
\hline
\end{tabular}

The main result emerging from the above tables can be summarized as follows: in both questionnaires there is a question getting less than $50 \%$ of the right answers from the students, it is the question on the verbal-linguistic section of the cognitive dimension; in both cases the students are asked to read and understand a given text and to translate it into a diagram. (i.e., the questions ask for the right translation of a text into a diagram where actions and objects are represented and hierarchical dependences among the different objects are given).

Data in the last two rows of the tables need further explanation. First, only $10 \%$ and $15 \%$ of the Benjamin and Junior students, respectively give the right answer to all the selected questions (the most representative). The last row states that only $5 \%$ and $3 \%$ of the same students rightly answer to the whole questionnaire.

Two main conclusions follow the above considerations:

- the difference in the students performances, when they have to face different questions (where different language and skills are needed and different categories intervene in the 
description of phenomena), confirms the relevance of the different languages they must know to be digitally competent,

- the same difference confirms the goodness of the structure of the cognitive dimension in the framework for the assessment of students' digital competence,

- whether students meet difficulties or do not succeed in giving the right answer, a feedback is obtained so that teachers and researchers can plan and make up further activities to help them overcome their difficulties.

\section{Students' Answers in the Affective Dimension}

As regards the questions in this dimension it has to be noted that almost all the questions were open, so that a great variety of different answers has been obtained from students; furthermore, this kind of questions didn't force students in the choice of an alternative, but sometimes induced them to reject the same question. As an example the case of a student is reported "I will not answer to this question because what I think is not relevant to you".

When considering students' answers the following remarks emerge.

As regards the most impressive question, more than $70 \%$ of Benjamin students chose one of the selected questions (i.e., the most representative for the cognitive section). The Juniors did not evidence similar preferences because their choices uniformly distributed all over the questions in the questionnaire.

When looking at the reasons guiding students to the choice of the most impressive question the following data have been obtained (Table 3):

\begin{tabular}{|l|c|c|}
\hline Table 3. Students' reasons for the most impressive question \\
\hline Options & $\begin{array}{c}\text { Benjamin } \\
\text { \% of answers }\end{array}$ & $\begin{array}{c}\text { Junior } \\
\text { \% of answers }\end{array}$ \\
\hline Originality of the situation & $26 \%$ & $14 \%$ \\
\hline The kind of the problem & $22 \%$ & $24 \%$ \\
\hline Difficulty of the question & $12 \%$ & $13 \%$ \\
\hline Difficulty in finding the solution & $10 \%$ & $11 \%$ \\
\hline $\begin{array}{l}\text { Quantity of information in the } \\
\text { question }\end{array}$ & $19 \%$ & $22 \%$ \\
\hline
\end{tabular}

In this case it is difficult to state the presence of relevant differences in the single series of data (only the Benjamin or only the Junior); it is easier to register variations in the behaviour of the students' groups, when passing from Benjamin to Junior: the interest for the originality of the situation decreases while the other reasons remain almost constant.

When asked for the level of the involvement in the possible change of a question the following answers have been obtained (Table 4): 


\begin{tabular}{|l|c|c|}
\hline Table 4. Students' involvement in the change of a question \\
\hline Options & $\begin{array}{c}\text { Benjamin } \\
\text { \% of choices }\end{array}$ & $\begin{array}{c}\text { Junior } \\
\text { \% of choices }\end{array}$ \\
\hline Autonomously & $10 \%$ & $10 \%$ \\
\hline With the help of a teacher & $9 \%$ & $6 \%$ \\
\hline With the help of friends & $10 \%$ & $4 \%$ \\
\hline With the help of relatives & $6 \%$ & -- \\
\hline $\begin{array}{l}\text { I don't know / I'll not change } \\
\text { anything }\end{array}$ & -- & $8 \%$ \\
\hline
\end{tabular}

Here too, there is a variation of tendency when passing from Benjamin to Junior students; the last ones think that friends and relatives are less important to get help for changing the question.

When requested of specifying the person/s they would have asked deeper explanations and clarifications, the following answers have been obtained (Table 5):

\begin{tabular}{|l|c|c|}
\hline Table 5. Students' requests of further/deeper explanations \\
\hline Options & $\begin{array}{c}\text { Benjamin } \\
\text { \% of choices }\end{array}$ & $\begin{array}{c}\text { Junior } \\
\text { \% of choices }\end{array}$ \\
\hline Expert (teacher or not) & $3 \%$ & $1 \%$ \\
\hline Mathematics teacher & $10 \%$ & $22 \%$ \\
\hline Informatics teacher & $4 \%$ & -- \\
\hline Humanities teacher & $2 \%$ & $3 \%$ \\
\hline Relatives & $3 \%$ & $4 \%$ \\
\hline
\end{tabular}

The distribution of the answers in the two sets of data describe the increase in the requests of help to the teacher of mathematics with respect to other teachers/persons when passing from Benjamin to Junior students.

At last, when asked for the possible topics to be included in the questionnaire the results in Table 6 were obtained (more than one option could be selected):

\begin{tabular}{|l|c|c|}
\hline Table 6. Possible topics to be included in the questionnaire \\
\hline Options & $\begin{array}{c}\text { Benjamin } \\
\text { \% of choices }\end{array}$ & $\begin{array}{c}\text { Junior } \\
\text { of choices }\end{array}$ \\
\hline Tools for text/number processing & $32 \%$ & $28 \%$ \\
\hline Tools for image processing & $27 \%$ & $22 \%$ \\
\hline $\begin{array}{l}\text { Tools for sound/movie manage- } \\
\text { ment }\end{array}$ & $24 \%$ & $13 \%$ \\
\hline $\begin{array}{l}\text { Connection of different IT/ICT } \\
\text { equipments }\end{array}$ & $23 \%$ & $18 \%$ \\
\hline Use of play station & $27 \%$ & $12 \%$ \\
\hline Internet & $30 \%$ & $32 \%$ \\
\hline
\end{tabular}


The main result, like in former situation, is the decrease of interest in two options: the tools managing sounds/movies and the play-stations, when passing from Benjamin to Junior students, the others remaining mostly constant.

\section{Conclusion and Future Studies}

The main results from the above section can be synthesized as follows:

- cognitive dimension:

a) the worst performances of the students come from the answers to the question on the verbal-linguistic section of the framework,

b) the little percentage of the right answers, both on all the selected questions and the whole questionnaires, indirectly demonstrate the presence of the different sections in the framework (i.e., technological, verbal-linguistic and logicalmathematical) and state for the dependence of the digital competence from the categories hypothesized (i.e., space, time and causality),

c) the difference in the number of positive answers to the various questions can be interpreted as a different development in the students of the competence in the corresponding sections of the cognitive dimension; alternatively it can be a consequence of the different ability in the use of the categories in that dimension (one hypothesis does not exclude the other, and both are contemporarily possible);

- affective dimension:

a) the use of the Krathwhol taxonomy shows that:

- the "receiving" level is can be detected in all the students who took part in the competition,

- the "responding" level is connected to the development of the competence depending on a given section of the cognitive dimension, at least when the students gives the right answer to a question,

- the "valuing" level can be detected in the students answering to the first questions (i.e., 1 to 3 ) in the affective section of the questionnaire,

- the "organizing" level is present in the students answering to questions from 4 to 6 in the affective section of the questionnaire,

- the "characterizing" level is shown by the student who actively participate in answering to the last question.

b) in all the issues proposed for the analysis of this dimension (i.e., student - questionnaire, student - discipline and student - digital technology interactions) a change is detected when passing from Benjamin to Junior students; this can be interpreted as:

- the age groups adopted in the "Beaver" contest are good enough for the assessment of digital competence,

- there are different "affective instances" when passing from the first age group to the second.

The main conclusion from the above remarks says that improvements are needed for the affective dimension to see if range of values (i.e., different scores or Likert scale) can be assigned to the different levels of the Krathwhol taxonomy.

Furthermore, when the work for the analysis of the socio-relational dimension will be completed and will be useful for the assessment of digital competence, we will be near the creation of new 
instruments for teaching-learning assessment. Until now the taxonomies used in education have been in fact the cognitive, the affective and the psychomotor, but new technologies have introduced elements assigning great importance to communication, social relations, subjects association and creation of communities. It can be hypothesized that the socio-relational dimension will contribute in the assessment of special features of digital competence in young generations and will help the development of good practices in the use of new technologies (i.e., IT/ICT technologies).

By now the new framework for digital competence assessment seems good enough to contribute in the analysis of students knowledge, skills and competences but a question still asks for an answer: can the questionnaire be the only instrument to be used to let students improve their digital competence?

In a project which will start soon, some Learning Objects on the topics in the questionnaire will be made available to students and teachers to help them in overcoming the difficulties they met in answering the questions.

\section{References}

Brown, A. L., \& Campione, J. (1996). Psychological theory and the design of innovative learning environments: On Procedure, principles and systems. In L. Schaube \& R. Glaser (Eds.), Innovation in learning (pp. 289-375). Mahwah, NJ: Erlbaum.

Bindé, J. Cotbett, J. \& Verity, B. (2005). 21st- century talks: Towards knowledge society. UNESCO.

Bloom, B. S. (1956). Taxonomy of educational objectives, Handbook I: The cognitive domain. New York: David McKay Co. Inc.

Calvani, A., Cartelli, A., Fini, A., \& Ranieri, M. (2008). Models and instruments for assessing digital competence at school. Journal of E-learning and Knowledge Society, 4(3), 183-193.

Cartelli, A. (2009). Frameworks for digital literacy and digital competence assessment. Proceedings of European Conference on e-Learning (ECEL 2009), University of Bari (Italy), Oct 29-30, 2009, pp. 116-123.

Cartelli, A., Dagiene, V., \& Futschek, G. (in press). Bebras contest and digital competence assessment: Analysis of frameworks. International Journal of Digital Literacy and Digital Competence, 1(1).

European Parliament and Council. (2005). Recommendation on key competences for lifelong learning. Retrieved Dec $4^{\text {th }} 2008$ from http://ec.europa.eu/education/policies/2010/doc/keyrec en.pdf

Gardner, H. (1993) Multiple intelligences: The theory in practice. New York: Basic Books.

Guidolin, U. (2005). Pensare digitale. Teoria e tecniche dei nuovi media. Milan, Italy: Mc Graw-Hill.

Janney, R., \&Snell, M. E. (2006). Social relationships and peer support (Teachers' guides to inclusive practices). Baltimore, MD: Paul H. Brookes.

Krathwohl, D. R., Bloom, B. S., \& Masia, B. B. (1973) Taxonomy of educational objectives, the Classification of Educational Goals. Handbook II: Affective Domain. New York: David McKay Co. Inc.

Le Boterf, G. (1990). De la compétence: Essai sur un attracteur étrange. Paris: Les Ed. de l'Organisation

Martin, A. (2005). DigEuLit - a European framework for digital literacy: A progress report. JeLit, Journal of eLiteracy, 2(2). Retrieved Dec 4, 2009 from http://www.jelit.org/65/01/JeLit_Paper_31.pdf

Piaget, J. (1970) Lo sviluppo mentale del bambino. Turin, Italy: Einaudi. 


\section{Biography}

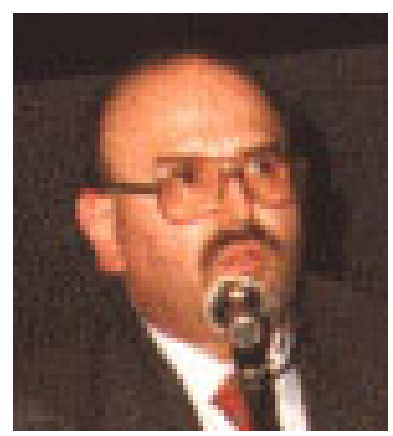

Antonio Cartelli is a researcher in Didactics and special pedagogy. He manages the Laboratory for Teaching-Learning Technologies and the Centre for ICT and on line teaching in the Faculty of Humanities at the University of Cassino - Italy. Among his interests are: misconceptions, mental schemes, Information Systems for research and teaching, Web Technologies in teaching research and their everyday application for the improvement of teaching and learning. He is also author of many papers and books concerning the themes he is interested in. 